\title{
Graft choice for isolated MPFL reconstruction: gracilis versus semitendinosus
}

\author{
Filippo Migliorini ${ }^{1}$ (D) Andromahi Trivellas ${ }^{2} \cdot$ Arne Driessen $^{1} \cdot$ Valentin Quack $^{1} \cdot$ Markus Tingart $^{1} \cdot$ Jörg Eschweiler $^{1}$
}

Received: 7 November 2019 / Accepted: 29 January 2020

(c) The Author(s) 2020, corrected publication 2021

\begin{abstract}
Introduction After the first patellar dislocation, most patients report damage of the medio-patellofemoral ligament (MPFL) and surgical reconstruction is required. The purpose of this study is to systematically review current evidence and to clarify the role of the gracilis and semitendinosus tendons as graft for isolated MPFL reconstruction.

Materials and methods The present systematic review was conducted according to the PRISMA guidelines. The literature search was conducted in October 2019. All clinical trials using the semitendinosus and/or gracilis tendon grafts for isolated MPFL reconstruction in patients with patellofemoral instability were considered for inclusion. Only articles reporting a minimum of 12-month follow-up were considered. The PEDro score was used for the methodological quality assessment.

Results Data from 1491 procedures were collected. The mean follow-up was 36.12 months. There was comparability among the patient baseline. All the scores of interests (Kujala, Tegner, Lysholm) and range of motion scored better in the semitendinosus group. Moreover, in favour of the semitendinosus group, a statistically significant reduction of the revision surgeries and re-dislocations were evidenced. Apprehension test and persistent instability sensation found any statistical correlations. Conclusion Isolated MPFL reconstruction through semitendinosus tendon graft performed better than the gracilis in selected patients suffering from recurrent patellofemoral instability.
\end{abstract}

Keywords Patellofemoral instability $\cdot$ MPFL reconstruction $\cdot$ Semitendinosus $\cdot$ Gracilis $\cdot$ Tendon $\cdot$ Graft

\section{Introduction}

Patellofemoral instability is a common cause of complaint in active young patients [1]. After the first dislocation, in about $96 \%$ of patients, the medial patellofemoral ligament (MPFL) is significantly damaged and surgical reconstruction can be necessary [2]. The reconstruction of the MPFL reports excellent results and patient satisfaction and is related to a low rate of complications and post-operative failures [3]. In conjunction, the centres performing MPFL reconstruction have doubled in the last decades [4]. For an optimal MPFL reconstruction, the graft choice is of fundamental importance. The graft can be harvested from several tendons,

Filippo Migliorini

migliorini.md@gmail.com

1 Department of Orthopaedics, RWTH Aachen University Clinic, Pauwelsstraße 30, 52074 Aachen, Germany

2 Department of Orthopaedics, David Geffen School of Medicine at UCLA, Suite 755, Los Angeles, CA 90095, USA auto- versus allograft or even synthetic graft. However, the most used grafts are the gracilis or semitendinosus tendons $[5,6]$. Semitendinosus and gracilis tendons are often preferred grafts for ligament reconstruction because of their intrinsic biomechanical proprieties [7], geometric proprieties [8], availability and low donor-site morbidity [9].

However, there is a lack of clinical studies comparing directly the two tendons, and the best graft for MPFL reconstruction is still unclear. The purpose of this study was to systematically review the current evidence and to investigate which is the best graft between gracilis and semitendinosus tendons for MPFL reconstruction. We focused on the clinical scores, physical examination, further revision surgeries and failures. 


\section{Materials and methods}

\section{Search strategy}

This systematic review of the literature was conducted according to the Preferred Reporting Items for Systematic Reviews and Meta-Analyses (PRISMA) [10]. The authors drafted a preliminary protocol to guide the search:

- (P) Population: recurrent patellofemoral instability;

- (I) Intervention: isolated MPFL reconstruction;

- (C) Comparison: semitendinosus versus gracilis tendon graft;

- (O) Outcomes: clinical score and examination, re-operations, failure.

\section{Literature search}

Two independent authors (FM, JE) performed the literature search. In October 2019, the following databases were accessed: Pubmed, Embase, Google Scholar, Scopus. The following keywords were used isolated or in combination: patellofemoral and/or patellar combined with instability, dislocation, luxation, syndrome combined with MPFL and/ or rupture, tear, reconstruction combined with semitendinosus, gracilis, hamstring, tendon, graft, combined with bundle, doubled, single. The same authors screened the resulting articles. If the title and related abstract matched the topic, the full text was accessed. Furthermore, the bibliographies were screened to find additional articles.

\section{Eligibility criteria}

All studies reporting the outcomes of MPFL reconstruction using the semitendinosus and/or gracilis tendon graft for recurrent patellofemoral instability were considered for inclusion. According to the Oxford Centre of EvidencedBased Medicine [11], levels of evidence I to IV were included. According to the authors' language capabilities, articles in English, German, Spanish, Italian and French were included. Only articles reporting data concerning isolated MPFL reconstruction that were included with a minimum of 12 months of follow-up were considered. Only articles reporting quantitative data under the outcomes of interest were considered for inclusion. Techniques, comments, letters, editorials, protocols and guidelines were excluded. Biomechanical, animal and cadaveric studies were also excluded. Articles reporting data on patellofemoral instability after total knee arthroplasty were excluded. Articles reporting data of revision surgeries were also rejected. Articles combining MPFL reconstruction with other proximal or distal alignment were excluded. Disagreements between the authors were debated and solved by a third author (AD).

\section{Outcomes of interest}

Two independent authors (FM, JE) extracted the following data: generalities (author, year, type study), patient demographics (number of knees, mean age), follow-up duration, onset (recurrent or acute), presence of risk factors, patellar and femoral graft fixation. The following outcomes of interest were collected: Kujala Anterior Knee Pain Scale [12], Lysholm Knee Scoring Scale [13], Tegner Activity Scale [14]. In addition, apprehension test, range of motion (ROM), persistent sensation of instability, revisions and redislocations were recorded.

\section{Methodological quality assessment}

The PEDro score was used for the methodological quality assessment. Two authors (FM, JE) independently performed the score. This score analysed the papers under several items: clear statement of inclusion and exclusion criteria, allocation, randomization, blinding methods, follow-up duration, point estimates and variability. The final result was a value from 0 (poor quality) to 10 (excellent quality). Values $>6$ points were considered acceptable (high quality $=10-8$; good quality: $8-6$; fair quality $=6-4$; poor quality $\leq 3$ ).

\section{Statistical analysis}

For the statistical analysis, we referred to the IBM SPSS Software. The arithmetic mean and standard deviation (SD) for continuous variables were adopted. For binary variables, the odd ratio (OR) effect measure was adopted. The confidence interval was set at $95 \%$ in all the binary comparisons. The unpaired $T$ test was performed in all the comparisons, with values of $P<0.05$ considered statistically significant.

\section{Results}

\section{Search result}

The initial literature search resulted in 894 articles. Of them, 379 were rejected because of duplications. Another 360 were rejected as they did not match the eligibility criteria. A further 107 articles were rejected because no quantitative data under the endpoints of interest were reported. Other 11 articles were rejected due to unreliable data. Ultimately, a total of 37 papers were included in this work, 11 using the gracilis tendon graft and 26 using the semitendinosus tendon graft (Fig. 1). 
Fig. 1 Flow-chart of the literature search
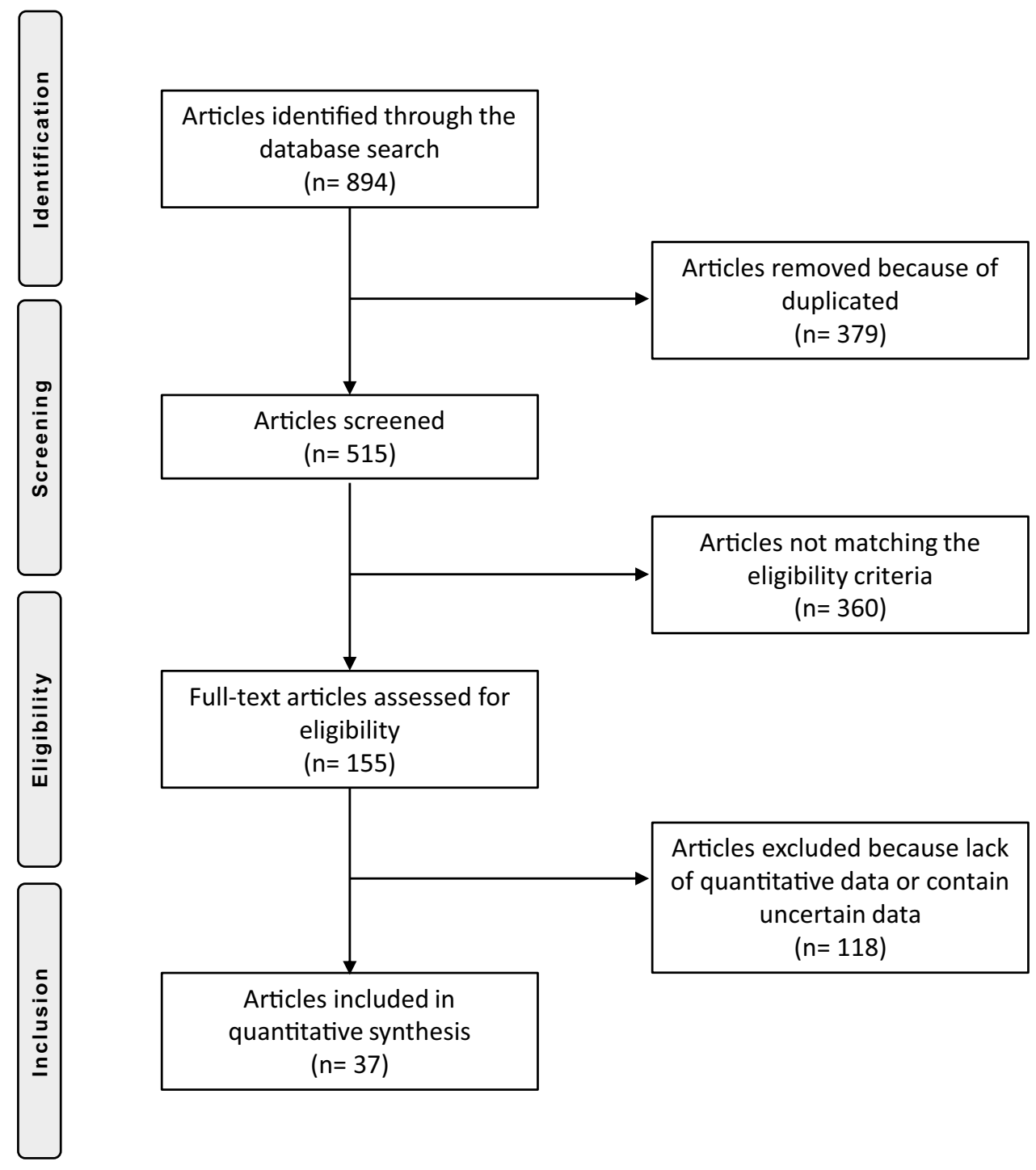

\section{Methodological quality assessment}

The methodology quality assessment showed several limitations. First, only $8 \%$ of the enrolled studies provided a randomization of the samples. Furthermore, no study provided a blinding method of the samples, limiting the quality of the overall results. Strength points included the length of followup and the well-designed analysis performed by most of the included papers. Moreover, most articles included a large number of patients in their studies. Consequently, the PEDro score resulted in 6.03 points, attesting to this work a good methodological quality assessment. The results of the PEDro score assigned for each study are shown in Tables 1 and 2.

\section{Patient demographics}

In the present study, a total of 1491 MPFL reconstructions, with a mean of $36.12 \pm 17.1$ months of follow-up, were enrolled. In the gracilis graft group, a total of 574 knees were analysed, with a mean age of $22.39 \pm 4.8$ years. In the semitendinosus graft group, a total of 917 knees were analysed, with a mean age of $22.68 \pm 7.4$ years. Between the two groups, there were no significant differences among the samples ages $(P=0.5)$, attesting a good baseline comparability. Patient demographics concerning the gracilis tendon graft group are shown in Table 1. Patient demographics concerning the semitendinosus tendon graft group are shown in Table 2.

\section{Outcomes of interest}

In the gracilis group, the Kujala score showed a mean of 84.95\% (SD 6.5), the Lysholm score 86.73\% (SD 4.2), and the Tegner 5.20 points (SD 0.9), the ROM $121.55^{\circ}$ (SD 6.2). In the semitendinosus group, the Kujala score showed a mean of $89.44 \%$ (SD 6.1,), the Lysholm score $91.17 \%$ (SD 
Table 1 Generalities, baseline demographics and related PEDro scores of the included articles reporting data of MPFL reconstruction using a gracilis tendon graft

\begin{tabular}{|c|c|c|c|c|c|c|c|}
\hline References & Type of study & PEDro score & Knees $(n)$ & Mean age & Mean follow-up & Patellar fixation & Femoral fixation \\
\hline \multirow[t]{2}{*}{ Astur et al. [15] } & \multirow[t]{2}{*}{ RCT } & \multirow[t]{2}{*}{8} & 30 & 31.06 & \multirow[t]{2}{*}{60.00} & Endobutton & Interference screw \\
\hline & & & 28 & 28.32 & & Anchor & Interference screw \\
\hline Bitar et al. [16] & PCS & 7 & 56 & 23.00 & 19.30 & Anchor & Interference screw \\
\hline Christiansen et al. [17] & PCS & 6 & 32 & 22.00 & 22.00 & Bone tunnel & Interference screw \\
\hline Hinterwimmer et al. [18] & RCS & 6 & 19 & 23.00 & 16.00 & Bone tunnel & Interference screw \\
\hline Kim et al. [19] & RCS & 6 & 9 & 24.60 & 19.30 & Soft tissue & Suture anchor \\
\hline Krishna Kumar et al. [20] & PCS & 7 & 30 & 18.00 & 25.00 & Endobutton & Interference screw \\
\hline \multirow[t]{2}{*}{ Lind et al. [21] } & \multirow[t]{2}{*}{ PCS } & \multirow[t]{2}{*}{8} & 24 & 12.50 & 39.00 & Bone tunnel & Soft tissue \\
\hline & & & 179 & 23.00 & 41.00 & Bone tunnel & Interference screw \\
\hline Lippacher et al. [22] & RCS & 7 & 68 & 18.30 & 24.70 & Bone tunnel & Interference screw \\
\hline Thaunat et al. [23] & RCS & 5 & 23 & 22.00 & 28.00 & Bone tunnel & Suture anchor \\
\hline Wagner et al. [24] & PCS & 6 & 50 & 19.00 & 12.00 & Suture anchor & Interference screw \\
\hline Wang et al. [25] & RCS & 6 & 26 & 26.30 & 38.20 & Suture anchor & Interference screw \\
\hline
\end{tabular}

$R C T$ randomized clinical trial, $P C S$ prospective cohort study, $R C S$ retrospective cohort study, $C S$ case series

Table 2 Results of continuous data

\begin{tabular}{lrrrr}
\hline Outcome & Gracilis $(n=574)$ & $\begin{array}{l}\text { Semiten- } \\
\text { dinosus } \\
(n=917)\end{array}$ & \multicolumn{1}{l}{$\Delta$} & $P$ \\
\hline Kujala score & $84.95 \pm 6.5$ & $89.44 \pm 6.1$ & 4.49 & 0.02 \\
Lysholm score & $86.73 \pm 4.2$ & $91.17 \pm 4.2$ & 4.44 & 0.04 \\
Tegner score & $5.20 \pm 0.9$ & $5.85 \pm 1.1$ & 0.65 & 0.2 \\
$\begin{array}{l}\text { Range of motion } \\
\text { (ROM) }\end{array}$ & $121.55 \pm 6.2$ & $134.97 \pm 6.8$ & 13.42 & 0.004 \\
\hline
\end{tabular}

4.2), and the Tegner 5.85 points (SD 1.1), the ROM $134.97^{\circ}$ (SD 6.8). All the scores of interests resulted in favour of the semitendinosus group: Kujala $+4.49 \%(P=0.02)$, Lysholm $+4.44 \%(P=0.04)$, Tegner +0.65 points $(P=0.2)$, ROM $+13.42^{\circ}(P=0.004)$.

In favour of the semitendinosus group, a reduction of the revision surgeries (OR 0.57; 95\% CI 0.2853 to 1.1594; $P=0.01)$ and re-dislocations (OR $0.19 ; 95 \%$ CI 0.0539 to $0.6993 ; P=0.01)$ were evidenced. The gracilis reported a not statistically significant reduction of the post-operative apprehension test (OR $1.14 ; 95 \%$ CI 0.6774 to $1.9048 ; P=0.6$ ), reduction of the persistent instability sensation (OR 1.24; $95 \%$ CI 0.4440 to $3.4691 ; P=0.7)$. Continuous comparisons are shown in Table 3, while binary in Table 4.

\section{Discussion}

According to the main findings of this systematic review, we found that the semitendinosus tendon graft performed better overall. Worthy of note was the statistically significant reduction of re-dislocations and revisions rate observed in the semitendinosus group. The endpoints Kujala and Lysholm and range of motion were both statistically significant in favour of the semitendinosus graft group. They showed homogenous values, with poor data variance and small confidence intervals, yielding trustworthy results. Concerning the other analysed endpoints, apprehension test and persistent instability sensation, no statistical differences between the two groups were found.

The MPFL is the most important restraint to patellar lateralization during the first $30^{\circ}$ of flexion $[52,53]$. Current literature reported no clinical study comparing directly the two grafts. However, the biomechanical proprieties of the grafts have been investigated. The study of Mountney et al. [54] stated that the MPFL ruptured at a mean of $26 \pm 7 \mathrm{~mm}$, and the patella dislocated at approximately $50 \mathrm{~mm}$, ensuring an MPFL rupture [54]. Graft choice is of fundamental importance for MPFL reconstruction. Tendon tensile strength and viscoelastic properties are some of the most important mechanical parameters to respect when choosing a graft for a successful ligament reconstruction. The MPFL is a ligament of tissue connecting the tubercle of the adductor on the femur epicondyle to the proximal medial edge of the patella [55]. Although a small structure, this ligament shows a remarkable tensile strength and viscoelasticity. As the native tensile strength of the MPFL is approximately $208 \mathrm{~N}[54,56]$, both gracilis and semitendinosus tendon grafts are far more resistant [5, 6]. In fact, the estimated tensile strength of the semitendinosus and gracilis tendon is $1216 \mathrm{~N}$ and $838 \mathrm{~N}$, respectively [57]. The semitendinosus tendon graft has more resistance to traction than the gracilis [58]. Therefore, the semitendinosus represents the most commonly used graft for MPFL reconstruction [59, 60]. However, interest concerning gracilis tendon grafts has 
Table 3 Generalities, baseline demographics, and related PEDro scores of the included articles reporting data of MPFL reconstruction using a semitendinosus tendon graft

\begin{tabular}{|c|c|c|c|c|c|c|c|}
\hline References & Type of study & PEDro score & Knees $(n)$ & Mean age & Mean follow-up & Patellar fixation & Femoral fixation \\
\hline Ahmad et al. [26] & CS & 5 & 20 & 23.00 & 31.00 & Bone tunnel & Interference screw \\
\hline Amin et al. [27] & RCS & 6 & 8 & 22.00 & 24.00 & Bone tunnel & Interference screw \\
\hline Ballal et al. [28] & PCS & 7 & 20 & 24.40 & 12.00 & Anchor & Interference screw \\
\hline \multirow{2}{*}{$\begin{array}{l}\text { Biondi Pinheiro et al. } \\
\text { [29] }\end{array}$} & \multirow[t]{2}{*}{ RCS } & \multirow[t]{2}{*}{7} & 16 & 27.10 & 31.20 & Anchor & Interference screw \\
\hline & & & 21 & 26.40 & 34.80 & Anchor & Interference screw \\
\hline Csintalan et al. [30] & CS & 5 & 56 & 24.30 & 51.00 & Bone tunnel & Interference screw \\
\hline Deie et al. [31] & RCS & 5 & 31 & 22.20 & 39.00 & Soft tissue & Bone plug \\
\hline Gomes et al. [32] & PCS & 6 & 16 & 26.70 & 60.00 & Bone tunnel & Soft tissue \\
\hline Gomes et al. [33] & PCS & 7 & 12 & 19.30 & 53.00 & Bone tunnel & Soft tissue \\
\hline Goncaives et al. [34] & PCS & 6 & 22 & 28.60 & 26.20 & Bone tunnel & Interference screw \\
\hline Han et al. [35] & RCS & 6 & 59 & 24.30 & 68.40 & Bone tunnel & Interference screw \\
\hline Howells et al. [36] & PCS & 7 & 155 & 26.00 & 16.00 & Bone tunnel & $\begin{array}{l}\text { Endobutton/Interference } \\
\text { screw }\end{array}$ \\
\hline Kang et al. [37] & $\mathrm{RCT}$ & 8 & 82 & 28.75 & 24.00 & Soft tissue & Interference screw \\
\hline Kita et al. [38] & PCS & 7 & 44 & 25.40 & 39.00 & Bone tunnel & Interference screw \\
\hline Kumahashi et al. [39] & PCS & 6 & 5 & 13.60 & 27.80 & Interference screw & Interference screw \\
\hline Kumahashi et al. [40] & PCS & 7 & 17 & 22.00 & 45.00 & Interference screw & Interference screw \\
\hline Lin et al. [41] & RCS & 5 & 18 & $\mathrm{~N} / \mathrm{R}$ & 35.00 & Suture anchor & Interference screw \\
\hline Ma et al. [42] & $\mathrm{RCT}$ & 8 & 32 & 28.40 & 40.00 & Anchor & Interference screw \\
\hline \multirow[t]{2}{*}{ Matsushita et al. [43] } & \multirow[t]{2}{*}{ RCS } & \multirow[t]{2}{*}{6} & 21 & 22.10 & 44.00 & Anchor & Interference screw \\
\hline & & & 18 & 23.50 & 38.00 & Anchor & Interference screw \\
\hline Niu et al. [44] & PCS & 7 & 30 & 25.00 & 55.10 & Bone tunnel & Interference screw \\
\hline Nomura et al. [45] & RCS & 6 & 12 & 24.80 & 51.00 & Bone tunnel & Suture anchor \\
\hline Panni et al. [46] & CS & 5 & 48 & 25.00 & 33.00 & Bone tunnel & $\begin{array}{l}\text { Interference screw or } \\
\text { anchor }\end{array}$ \\
\hline Raghuveer et al. [47] & PCS & 7 & 15 & 29.20 & 42.00 & Bone tunnel & $\begin{array}{l}\text { Interference screw or } \\
\text { anchor }\end{array}$ \\
\hline Sadigursky et al. [48] & PCS & 7 & 31 & 29.38 & 12.00 & Anchor & Interference screw \\
\hline Toritsuka et al. [49] & $\mathrm{CS}$ & 6 & 20 & 23.80 & 30.00 & Bone tunnel & Endobutton \\
\hline Wang et al. [50] & RCS & 7 & 28 & 29.00 & 42.00 & Anchor & Interference screw \\
\hline Zhang et al. [51] & PCS & 7 & 60 & 21.00 & 96.00 & Suture anchor & Interference screw \\
\hline
\end{tabular}

$R C T$ randomized clinical trial, $P C S$ prospective cohort study, $R C S$ retrospective cohort study, $C S$ case series

Table 4 Results of binary data

\begin{tabular}{llll}
\hline Outcome & OR & 95\% CI & $P$ \\
\hline Revisions & 0.57 & 0.2853 to 1.1594 & 0.01 \\
Re-dislocations & 0.19 & 0.0539 to 0.6993 & 0.01 \\
Apprehension test & 1.14 & 0.6774 to 1.9048 & 0.06 \\
Persistent instability sensation & 1.24 & 0.4440 to 3.4691 & 0.07 \\
\hline
\end{tabular}

recently grown [6]: despite being weaker than the semitendinosus tendon, the gracilis tendon has shown a stiffness value closer to that of the MPFL ligament $[6,61]$. Tendon stiffness is the ratio of the force response to the displacement of the myotendinous complex (force change/length change, $\mathrm{N} / \mathrm{m}$ ) [62]. The elastic modulus (slope of the linear portion of the stress-strain curve) of the MPFL has been investigated by two biomechanical studies. Smeets et al. [63] reported the elastic modulus of the MPFL to be 294.6 MPa. Another study conducted by Criscenti et al. [64] stated the elastic modulus of the MPFL to be $116 \mathrm{MPa}$. The elastic modulus of the semitendinosus and gracilis has been also investigated in biomechanical studies. Smeets et al. [65] reported an elastic modulus of $1036 \mathrm{MPa}$ versus $1458 \mathrm{MPa}$, respectively. Abramowitch et al. [5] detected an elastic modulus of 484.5 MPa versus 625.5 MPa, while Butler et al. [66] 362.2 MPa versus 612.8 MPa for the semitendinosus and gracilis tendons, respectively. These data confirmed that the semitendinosus provides more resistance to the traction, with reduced elastic modulus compared to both MPFL and gracilis tendon. In selected patients suffering from patellofemoral instability, the resulting lateralizing forces weighing on MPFL are greater than those on a healthy knee. The 
reconstruction via the semitendinosus tendon graft, being more resistant than MPFL and gracilis, can therefore explain the reduced tendency to re-dislocations and revisions. Therefore, according to the present results, the usage of the semitendinosus tendon graft should be encouraged.

The present systematic review evidenced important limitations. The overall poor quality of the included studies represented an important point of weakness. No study took advantage of blinding methods, and only $8 \%$ provided randomization of the samples. Therefore, the data must be interpreted with caution. There is a lack of randomized clinical trials in the current literature, and further high-quality studies are strongly required. The present study performed the analyses regardless of the type of onset of instability, type of patellar and femoral fixation. This represents another limitation of the present work, and further studies are required. Points of strength of this systematic review were the comprehensive nature of the literature search, along with the strict eligibility criteria and rigorous quality assessment. Another point of strength, the methodological assessment of this work, which according to the PEDro score, resulted in a good quality assessment. Furthermore, as confirmed by the Student's t-test, the study presents an optimal baseline comparability of the samples. All these observations provide an overall reduction of the risk of publication bias, generating feasible results.

\section{Conclusion}

For isolated MPFL reconstruction, the semitendinosus performed better overall. The Kujala and Lysholm scores were both statistically significant in favour of the semitendinosus graft group. The ROM was statistically significant and greater in favour of the semitendinosus graft group. Furthermore, a statistically significant reduction in the failure rate was observed in the semitendinosus group. The gracilis tendon graft group reported a reduction in complication rate, but without statistical significance.

Funding No external source of funding was used.

\section{Compliance with ethical standards}

Conflict of interest The authors declare that they have no conflicts of interest.

Ethical approval This article does not contain any studies with human participants or animals performed by any of the authors.

Informed consent For this type of study, informed consent is not required.
Open Access This article is licensed under a Creative Commons Attribution 4.0 International License, which permits use, sharing, adaptation, distribution and reproduction in any medium or format, as long as you give appropriate credit to the original author(s) and the source, provide a link to the Creative Commons licence, and indicate if changes were made. The images or other third party material in this article are included in the article's Creative Commons licence, unless indicated otherwise in a credit line to the material. If material is not included in the article's Creative Commons licence and your intended use is not permitted by statutory regulation or exceeds the permitted use, you will need to obtain permission directly from the copyright holder. To view a copy of this licence, visit http://creativecommons.org/licenses/by/4.0/.

\section{References}

1. Sillanpää PMV, Iivonen T et al (2008) Incidence and risk factors of acute traumatic primary patellar dislocation. Med Sci Sports Exerc 40(4):606-611

2. Nomura E, Horiuchi Y, Inoue M (2002) Correlation of MR imaging findings and open exploration of medial patellofemoral ligament injuries in acute patellar dislocations. Knee 9(2):139-143

3. Reagan J, Kullar R, Burks R (2015) MPFL reconstruction: technique and results. Orthop Clin North Am 46(1):159-169. https://doi.org/10.1016/j.ocl.2014.09.012

4. Stupay KL, Swart E, Shubin Stein BE (2015) Widespread implementation of medial patellofemoral ligament reconstruction for recurrent patellar instability maintains functional outcomes at midterm to long-term follow-up while decreasing complication rates: a systematic review. Arthroscopy 31(7):1372-1380. https://doi.org/10.1016/j.arthro.2014.12.029

5. Abramowitch SD, Zhang X, Curran M, Kilger R (2010) A comparison of the quasi-static mechanical and non-linear viscoelastic properties of the human semitendinosus and gracilis tendons. Clin Biomech (Bristol, Avon) 25(4):325-331. https://doi.org/10. 1016/j.clinbiomech.2009.12.007

6. Kyung HS, Kim HJ (2015) Medial patellofemoral ligament reconstruction: a comprehensive review. Knee Surg Relat Res 27(3):133-140. https://doi.org/10.5792/ksrr.2015.27.3.133

7. West RV, Harner CD (2005) Graft selection in anterior cruciate ligament reconstruction. J Am Acad Orthop Surg 13(3):197-207

8. Coobs BR, LaPrade RF, Griffith CJ, Nelson BJ (2007) Biomechanical analysis of an isolated fibular (lateral) collateral ligament reconstruction using an autogenous semitendinosus graft. Am J Sports Med 35(9):1521-1527. https://doi.org/10. $1177 / 0363546507302217$

9. Maletis GB, Cameron SL, Tengan JJ, Burchette RJ (2007) A prospective randomized study of anterior cruciate ligament reconstruction: a comparison of patellar tendon and quadruplestrand semitendinosus/gracilis tendons fixed with bioabsorbable interference screws. Am J Sports Med 35(3):384-394. https:// doi.org/10.1177/0363546506294361

10. Moher D, Liberati A, Tetzlaff J, Altman DG, Group P (2009) Preferred reporting items for systematic reviews and meta-analyses: the PRISMA statement. BMJ 339:b2535. https://doi.org/ 10.1136/bmj.b2535

11. Howick JCI, Glasziou P, Greenhalgh T, Heneghan C, Liberati A, Moschetti I, Phillips B, Thornton H, Goddard O, Hodgkinson M (2011) The 2011 Oxford Levels of Evidence. Oxford Centre for Evidence-Based Medicine. https://www.cebmnet/indexaspx?o= 5653. Accessed Oct 2019

12. Kujala UM, Jaakkola LH, Koskinen SK, Taimela S, Hurme M, Nelimarkka O (1993) Scoring of patellofemoral disorders. Arthroscopy 9(2):159-163 
13. Lysholm J, Gillquist J (1982) Evaluation of knee ligament surgery results with special emphasis on use of a scoring scale. Am J Sports Med 10(3):150-154. https://doi.org/10.1177/03635 4658201000306

14. Briggs KK, Lysholm J, Tegner Y, Rodkey WG, Kocher MS, Steadman JR (2009) The reliability, validity, and responsiveness of the Lysholm score and Tegner activity scale for anterior cruciate ligament injuries of the knee: 25 years later. Am J Sports Med 37(5):890-897. https://doi.org/10.1177/0363546508330143

15. Astur DC, Gouveia GB, Borges JH, Astur N, Arliani GG, Kaleka CC, Cohen M (2015) Medial patellofemoral ligament reconstruction: a longitudinal study comparison of 2 techniques with 2 and 5-years follow-up. Open Orthop J 9:198-203. https:// doi.org/10.2174/1874325001509010198

16. Bitar AC, D'Elia CO, Demange MK, Viegas AC, Camanho GL (2011) Randomized prospective study on traumatic patellar dislocation: conservative treatment versus reconstruction of the medial patellofemoral ligament using the patellar tendon, with a minimum of two years of follow-up. Revista Brasileira de Ortopedia (English Edition) 46(6):675-683. https://doi.org/10. 1016/s2255-4971(15)30324-4

17. Christiansen SE, Jacobsen BW, Lund B, Lind M (2008) Reconstruction of the medial patellofemoral ligament with gracilis tendon autograft in transverse patellar drill holes. Arthroscopy 24(1):82-87. https://doi.org/10.1016/j.arthro.2007.08.005

18. Hinterwimmer S, Imhoff AB, Minzlaff P, Saier T, Rosenstiel N, Hawe W, Feucht MJ (2013) Anatomical two-bundle medial patellofemoral ligament reconstruction with hardware-free patellar graft fixation: technical note and preliminary results. Knee Surg Sports Traumatol Arthrosc 21(9):2147-2154. https:// doi.org/10.1007/s00167-013-2498-8

19. Kim TS, Kim HJ, Ra IH, Kyung HS (2015) Medial patellofemoral ligament reconstruction for recurrent patellar instability using a gracilis autograft without bone tunnel. Clin Orthop Surg 7(4):457-464. https://doi.org/10.4055/cios.2015.7.4.457

20. Krishna Kumar M, Renganathan S, Joseph CJ, Easwar T, Rajan DV (2014) Medial patellofemoral ligament reconstruction in patellar instability. Indian J Orthop 48(5):501-505. https://doi. org/10.4103/0019-5413.139864

21. Lind M, Enderlein D, Nielsen T, Christiansen SE, Fauno P (2016) Clinical outcome after reconstruction of the medial patellofemoral ligament in paediatric patients with recurrent patella instability. Knee Surg Sports Traumatol Arthrosc 24(3):666-671. https://doi.org/10.1007/s00167-014-3439-x

22. Lippacher S, Dreyhaupt J, Williams SR, Reichel H, Nelitz M (2014) Reconstruction of the medial patellofemoral ligament: clinical outcomes and return to sports. Am J Sports Med 42(7):1661-1668. https://doi.org/10.1177/0363546514529640

23. Thaunat M, Erasmus PJ (2007) The favourable anisometry: an original concept for medial patellofemoral ligament reconstruction. Knee 14(6):424-428. https://doi.org/10.1016/j.knee.2007. 08.008

24. Wagner D, Pfalzer F, Hingelbaum S, Huth J, Mauch F, Bauer G (2013) The influence of risk factors on clinical outcomes following anatomical medial patellofemoral ligament (MPFL) reconstruction using the gracilis tendon. Knee Surg Sports Traumatol Arthrosc 21(2):318-324. https://doi.org/10.1007/ s00167-012-2015-5

25. Wang HD, Dong JT, Gao SJ (2016) Medial patellofemoral ligament reconstruction using a bone groove and a suture anchor at patellar: a safe and firm fixation technique and 3-year follow-up study. J Orthop Surg Res 11(1):138. https://doi.org/10.1186/ s13018-016-0473-z

26. Ahmad CS, Brown GD, Shubin Stein BE (2009) The docking technique for medial patellofemoral ligament reconstruction: surgical technique and clinical outcome. Am J Sports Med 37(10):2021-2027. https://doi.org/10.1177/0363546509336261

27. Mohamed Hamed Fahmy AHA (2015) Minimal invasive medial patellofemoral ligament reconstruction by hamstring tendon auto-graft. Orthopedic \& Muscular System. https://doi.org/10. 4172/2161-0533.1000182

28. Ballal M, Vamsinath P, Basha N (2018) Functional outcome of medial patellofemoral ligament injury (MPFL) reconstruction in recurrent patellar dislocation. Int J Orthop Sci 4(4):204-207. https://doi.org/10.22271/ortho.2018.v4.i4d.38

29. Pinheiro Junior LFB, Cenni MHF, Nicolai OP, Gomes LPH, Leal RS, Coelho DGP (2018) Outcomes of medial patellofemoral ligament reconstruction in patients with patella alta. Rev Bras Ortop 53(5):570-574. https://doi.org/10.1016/j.rboe.2017. 06.014

30. Csintalan RP, Latt LD, Fornalski S, Raiszadeh K, Inacio MC, Fithian DC (2014) Medial patellofemoral ligament (MPFL) reconstruction for the treatment of patellofemoral instability. J Knee Surg 27(2):139-146. https://doi.org/10.1055/s-0033-1360652

31. Deie M, Ochi M, Adachi N, Shibuya H, Nakamae A (2011) Medial patellofemoral ligament reconstruction fixed with a cylindrical bone plug and a grafted semitendinosus tendon at the original femoral site for recurrent patellar dislocation. Am J Sports Med 39(1):140-145. https://doi.org/10.1177/0363546510377436

32. Ellera Gomes JL, Stigler Marczyk LR, Cesar de Cesar P, Jungblut CF (2004) Medial patellofemoral ligament reconstruction with semitendinosus autograft for chronic patellar instability: a followup study. Arthroscopy 20(2):147-151. https://doi.org/10.1016/j. arthro.2003.11.006

33. Gomes JE (2008) Comparison between a static and a dynamic technique for medial patellofemoral ligament reconstruction. Arthroscopy 24(4):430-435. https://doi.org/10.1016/j.arthro. 2007.11.005

34. Gonçaives MBJ, Júnior LHdC, Soares LFM, Gonçaives TJ, dos Santos RL, Pereira ML (2011) Medial patellofemoral ligament reconstruction to treat recurrent patellar dislocation. Revista Brasileira de Ortopedia (English Edition) 46(2):160-164. https://doi. org/10.1016/s2255-4971(15)30233-0

35. Han H, Xia Y, Yun X, Wu M (2011) Anatomical transverse patella double tunnel reconstruction of medial patellofemoral ligament with a hamstring tendon autograft for recurrent patellar dislocation. Arch Orthop Trauma Surg 131(3):343-351. https://doi.org/ 10.1007/s00402-010-1173-5

36. Howells NR, Barnett AJ, Ahearn N, Ansari A, Eldridge JD (2012) Medial patellofemoral ligament reconstruction: a prospective outcome assessment of a large single centre series. J Bone Joint Surg Br 94(9):1202-1208. https://doi.org/10.1302/0301-620X.94B9. 28738

37. Kang H, Cao J, Yu D, Zheng Z, Wang F (2013) Comparison of 2 different techniques for anatomic reconstruction of the medial patellofemoral ligament: a prospective randomized study. Am J Sports Med 41(5):1013-1021. https://doi.org/10.1177/03635 46513480468

38. Kita K, Tanaka Y, Toritsuka Y, Amano H, Uchida R, Takao R, Horibe S (2015) Factors affecting the outcomes of double-bundle medial patellofemoral ligament reconstruction for recurrent patellar dislocations evaluated by multivariate analysis. Am J Sports Med 43(12):2988-2996. https://doi.org/10.1177/0363546515 606102

39. Kumahashi N, Kuwata S, Tadenuma T, Kadowaki M, Uchio Y (2012) A "sandwich" method of reconstruction of the medial patellofemoral ligament using a titanium interference screw for patellar instability in skeletally immature patients. Arch Orthop Trauma Surg 132(8):1077-1083. https://doi.org/10.1007/ s00402-012-1516-5 
40. Kumahashi N, Kuwata S, Takuwa H, Egusa N, Uchio Y (2016) Longitudinal change of medial and lateral patellar stiffness after reconstruction of the medial patellofemoral ligament for patients with recurrent patellar dislocation. J Bone Joint Surg Am 98(7):576-583. https://doi.org/10.2106/JBJS.15.00605

41. Lin KY, Lu YC, Renn JH (2015) The double-pulley technique for anatomical double-bundled medial patellofemoral ligament reconstruction. Injury 46(8):1619-1624. https://doi.org/10.1016/j. injury.2015.04.017

42. Ma LF, Wang F, Chen BC, Wang CH, Zhou JW, Wang HY (2013) Medial retinaculum plasty versus medial patellofemoral ligament reconstruction for recurrent patellar instability in adults: a randomized controlled trial. Arthroscopy 29(5):891-897. https://doi. org/10.1016/j.arthro.2013.01.030

43. Matsushita T, Kuroda R, Oka S, Matsumoto T, Takayama K, Kurosaka M (2014) Clinical outcomes of medial patellofemoral ligament reconstruction in patients with an increased tibial tuberosity-trochlear groove distance. Knee Surg Sports Traumatol Arthrosc 22(10):2438-2444. https://doi.org/10.1007/ s00167-014-2919-3

44. Niu J, Qi Q, Fu K, Duan G, Liu C, Wang F (2017) Medial patellofemoral ligament reconstruction with semi-patellar tunnel fixation: surgical technique and mid-term follow-up. Med Sci Monit 23:5870-5875. https://doi.org/10.12659/msm.905583

45. Nomura E, Inoue M (2006) Hybrid medial patellofemoral ligament reconstruction using the semitendinous tendon for recurrent patellar dislocation: minimum 3 years' follow-up. Arthroscopy 22(7):787-793. https://doi.org/10.1016/j.arthro.2006.04.078

46. Panni AS, Alam M, Cerciello S, Vasso M, Maffulli N (2011) Medial patellofemoral ligament reconstruction with a divergent patellar transverse 2-tunnel technique. Am J Sports Med 39(12):2647-2655. https://doi.org/10.1177/0363546511420079

47. Raghuveer RK, Mishra CB (2012) Reconstruction of medial patellofemoral ligament for chronic patellar instability. Indian J Orthop 46(4):447-454. https://doi.org/10.4103/0019-5413.97259

48. Sadigursky D, de Melo Laranjeira MS, Nunes M, Caneiro RJ, Colavolpe PO (2016) Reconstruction of the medial patellofemoral ligament by means of the anatomical double-bundle technique using metal anchors. Rev Bras Ortop 51(3):290-297. https://doi. org/10.1016/j.rboe.2015.07.011

49. Toritsuka Y, Amano H, Mae T, Uchida R, Hamada M, Ohzono K, Shino K (2011) Dual tunnel medial patellofemoral ligament reconstruction for patients with patellar dislocation using a semitendinosus tendon autograft. Knee 18(4):214-219. https://doi. org/10.1016/j.knee.2010.05.007

50. Wang F, Kang HJ, Chen BC, Chen W, Su YL, Zhang YZ (2010) Combination of medial patellofemoral ligament reconstruction with vastus medialis advancement for chronic patellar dislocation. Chin Med J (Engl) 123(21):3024-3029

51. Zhang L, Li Z (2019) Long-term clinical results of double bundle reconstruction of the medial patellofemoral ligament for patellar instability. J Knee Surg 32(2):153-159. https://doi.org/10.1055/s0038-1636913

52. Bicos J, Fulkerson JP, Amis A (2007) Current concepts review: the medial patellofemoral ligament. Am J Sports Med 35(3):484492. https://doi.org/10.1177/0363546507299237
53. Farr J, Schepsis AA (2006) Reconstruction of the medial patellofemoral ligament for recurrent patellar instability. J Knee Surg 19(4):307-316

54. Mountney J, Senavongse W, Amis AA, Thomas NP (2005) Tensile strength of the medial patellofemoral ligament before and after repair or reconstruction. J Bone Joint Surg Br 87(1):36-40

55. Tuxoe JI, Teir M, Winge S, Nielsen PL (2002) The medial patellofemoral ligament: a dissection study. Knee Surg Sports Traumatol Arthrosc 10(3):138-140. https://doi.org/10.1007/ s00167-001-0261-z

56. Burks RT, Desio SM, Bachus KN, Tyson L, Springer K (1998) Biomechanical evaluation of lateral patellar dislocations. Am J Knee Surg 11(1):24-31

57. Boniello MR, Schwingler PM, Bonner JM, Robinson SP, Cotter A, Bonner KF (2015) Impact of hamstring graft diameter on tendon strength: a biomechanical study. Arthroscopy 31(6):1084-1090. https://doi.org/10.1016/j.arthro.2014.12.023

58. Krebs C, Tranovich M, Andrews K, Ebraheim N (2018) The medial patellofemoral ligament: review of the literature. J Orthop 15(2):596-599. https://doi.org/10.1016/j.jor.2018.05.004

59. Amin NH, Lynch TS, Patel RM, Patel N, Saluan P (2015) Medial patellofemoral ligament reconstruction. JBJS Rev. https://doi.org/ 10.2106/jbjs.rvw.n.00089

60. Fink C, Veselko M, Herbort M, Hoser C (2014) MPFL reconstruction using a quadriceps tendon graft: part 2: operative technique and short term clinical results. Knee 21(6):1175-1179. https://doi. org/10.1016/j.knee.2014.05.006

61. Amis AA, Firer P, Mountney J, Senavongse W, Thomas NP (2003) Anatomy and biomechanics of the medial patellofemoral ligament. Knee 10(3):215-220

62. Cook CS, McDonagh MJ (1996) Measurement of muscle and tendon stiffness in man. Eur J Appl Physiol Occup Physiol 72(4):380-382. https://doi.org/10.1007/bf00599700

63. Smeets K, Slane J, Scheys L, Claes S, Bellemans J (2017) Mechanical analysis of extra-articular knee ligaments. Part one: native knee ligaments. Knee 24(5):949-956. https://doi.org/10. 1016/j.knee.2017.07.013

64. Criscenti G, De Maria C, Sebastiani E, Tei M, Placella G, Speziali A, Vozzi G, Cerulli G (2016) Material and structural tensile properties of the human medial patello-femoral ligament. J Mech Behav Biomed Mater 54:141-148. https://doi.org/10.1016/j. jmbbm.2015.09.030

65. Smeets K, Bellemans J, Scheys L, Eijnde BO, Slane J, Claes S (2017) Mechanical analysis of extra-articular knee ligaments. Part two: tendon grafts used for knee ligament reconstruction. Knee 24(5):957-964. https://doi.org/10.1016/j.knee.2017.07.011

66. Butler DL, Grood ES, Noyes FR, Zernicke RF, Brackett K (1984) Effects of structure and strain measurement technique on the material properties of young human tendons and fascia. J Biomech 17(8):579-596. https://doi.org/10.1016/0021-9290(84)90090-3

Publisher's Note Springer Nature remains neutral with regard to jurisdictional claims in published maps and institutional affiliations. 